\title{
Japanese eras
}

(There is little agreement as to the exact nomenclature and dates of the periods of Japanese history; the following is a rough guide.)

$\begin{array}{ll}\text { Jōmon: } & \text { To c.200 BC } \\ \text { Yayoi: } & 200 \text { BC-AD 250 } \\ \text { Kofun: } & 250-552 \\ \text { Yamato: } & 300-710 \\ \text { Asuka: } & 552-645 \\ \text { Nara: } & 645-794 \\ \text { Heian: } & 794-1185 \\ \text { Kamakura: } & 1185-1392 \\ \text { Muromachi: } & 1473-1568 \\ \text { Momoyama: } & 1568-1600 \\ \text { Tokugawa: } & 1600-1868 \\ \text { Modern: } & 1868 \text { to date } \\ \text { Meiji: } & 1868-1912 \\ \text { Taisho: } & 1912-26 \\ \text { Shōwa } & 1926-\end{array}$


